\title{
Influence of environmental factors and socio- psychological assistance to seafarers with signs of a professional burnout syndrome
}

\author{
Lilya Kemalova ${ }^{1, *}$, Marina Nikonorova \\ ${ }^{1} \mathrm{PhD}$, Department of Social Sciences and Social Work, Kerch State Maritime Technological \\ University, 82 Ordzhonikidze Str., 98309 Kerch, Russia
}

\begin{abstract}
The article deals with the problem of socio-psychological assistance to sailors with the syndrome of professional burnout. The specifics of the manifestation of burnout syndrome among seamen of fishing vessels, factors determining its formation and development are revealed. A program for the prevention of professional burnout syndrome has been proposed for seafarers with signs of professional burnout syndrome.
\end{abstract}

\section{Introduction}

Formulation of the problem. In recent decades, the concepts of "stress", "psychological burnout", and "depression" are increasingly used in the scientific literature. This is due to the fact that against the background of a general socio-economic, political, spiritual crisis that has gripped society as a whole, the relationship in the "person-to-person" system becomes more complex, which affects the psychological and social well-being of a person, causing stress and depression. This situation affects the professional activity of a person, leads to the appearance of the so-called "burnout syndrome" against the background of constant stress. Professional stressors include: high workload, danger and complexity of the profession, high level of personal and social responsibility.

All of these characteristics apply to the profession of a sailor, because it is associated with a permanent job in extreme conditions. Representatives of this profession, staying for a long time on a voyage, are under stress, extreme conditions and therefore may experience emotional and physical exhaustion. This is expressed in the depressed state, in the growth of dissatisfaction with oneself and one's work, and in the understating of self-esteem. This situation requires work not only to overcome the burnout syndrome that has already arisen, but also to develop preventive measures related to its prevention.

\section{Formation of the goal}

In this regard, the purpose of this article is to analyze the peculiarities of the manifestation of the professional burnout syndrome in representatives of the sea professions and to identify measures to provide them with social and psychological assistance. This goal is specified by

\footnotetext{
* Corresponding author: kemalova@yandex.ru
} 
the following tasks: 1) to explore various scientific approaches to the study of the phenomenon of professional burnout; 2) to determine the main measures for the provision of social and psychological assistance to seafarers whose profession is stressful.

"Burnout syndrome" is a complex psycho-physiological phenomenon, which is defined as emotional, mental and physical exhaustion due to prolonged emotional stress. The burnout syndrome is expressed in a depressed state, a feeling of fatigue and emptiness, a lack of energy and enthusiasm, a loss of the ability to see the positive results of your work, a negative attitude towards work and life in general $[6,7]$.

The concept of burnout by foreign and domestic psychologists is usually used to denote the state of physical, emotional, and mental exhaustion experienced by a person, caused by prolonged involvement in situations containing high emotional demands, which in turn are most often the result of a combination of excessively high emotional costs and chronic situational stresses.

Currently, there are about 100 symptoms, one way or another associated with "burnout". B. Pelman and E. Hartman, summarizing many definitions of "burnout," identified three main components: emotional exhaustion, depersonalization (cynicism) and a decrease in professional effectiveness (reduction of professional qualities) [9].

Boyko V.V. considers "burnout" as a psychological defense mechanism developed by an individual in the form of complete or partial exclusion of emotions in response to selected traumatic effects, an acquired stereotype of emotional, most often professional behavior. He also describes the various symptoms of "burnout" [6,7].

The symptom of "emotional deficiency." A professional comes to feeling that, emotionally, he can no longer help subjects of his activity.

The symptom of "emotional detachment." Personality almost completely excludes emotions from the sphere of professional activity.

The symptom of "personal detachment, or depersonalization." Manifested in a wide range of attitudes and actions of a professional in the process of communication. First of all, there is a complete or partial loss of interest in a person - the subject of professional action.

The symptom of "psychosomatic and psycho-vegetative disorders." As the name implies, the symptom manifests itself at the level of physical and mental well-being. Usually it is formed by a conditioned-reflex connection of a negative property.

\section{Theoretical analysis of the literature}

The theoretical analysis of the literature $[1,2,3,4,5]$ and the results of the survey allowed us to identify the factors that contribute to the emergence of stress among sailors, and as a result provoke the development of professional burnout syndrome. These factors can be divided into groups: macro-level, meso-level, and micro-level factors.

1. The group of macro-level factors is quite peculiar and specific for seafarers, this includes such factors as: predominantly indifferent attitude of society (including government) to seamen and their problems, loss of prestige of the seaman's profession, etc.

2. The factors of the meso-level consist of several groups: "Specificity of the content of the profession"; "Insufficient moral and material incentives"; "Physical and emotional stress"; "Organization and working conditions"; "Interpersonal relations in the team."

3. The factors of "professional burnout" at the micro level include such individually psychological characteristics of seafarers as communication barriers; self-regulation level; increased level of requirements, psychological personality characteristics, etc.

Istomina O.A., Nelyubin K.M. [9] The stressors of marine labor include: the threat of accidents and injuries; sensory deprivation (underutilization of the systems of our analyzers is observed in the conditions of the isolated space of the vessel); stressors arising from the interaction of man with the production environment of the vessel (noise level, natural and 
artificial illumination, electromagnetic radiation, vibration, gas pollution of the air environment); loss of important mental connections, relative social isolation; family stressors; stressors arising from the interaction of man with the socio-psychological environment of the crew; economic and commercial stressors; information hunger; the frustration of a number of physiological needs; hypodynamia and hypokinesia, monotony of activity; unity of zones of work and rest; jet lag; threat to life (pirates), sexual deprivation, food factors; high responsibility; round-the-clock execution of duties, constant readiness for action, etc. [9]

Therefore, the prevention of stress factors and professional burnout, as a result of exposure to stress, is relevant.

Results. Empirical research was carried out for 3 years on the basis of fishing vessels fishing in the waters of the Black and Azov Seas (from 2014 to 2017). The sample consisted of 82 sailors aged from 21 to 45 years. All subjects are men. Work experience in the profession - from 4 to 28 years. All the subjects for the last 3 years have been working without a full holiday, the working day is formally 8 hours, but in reality it is not normalized.

The most pronounced among sailors is the phase of resistance or resistance, when the person is trying to reduce the internal disturbing tension. In $81 \%$ of respondents - medium and high degree of formation of the phase of resistance (in $29 \%$ - the phase is fully formed, $52 \%$ - the phase is formed).

Regarding the symptoms of the resistance phase, $91 \%$ of respondents use inadequate selective emotional response as a maladaptive defensive strategy. It manifests itself in the fact that the sailor communicates and reacts to colleagues, subordinates and other people with whom he meets in the workplace, in accordance with his mood. $57.68 \%$ of respondents use a justification of emotional detachment from colleagues and relatives as a defensive strategy.

For $60.65 \%$ of the investigated manifestations of the reduction of professional duties. This symptom of emotional burnout is manifested in the fact that sailors avoid those forms of behavior and communication that require high emotional stress from them, but at the same time it is also connected with their professional duties.

Almost half of the sample ( $48 \%$ of subjects) at the significant level showed symptoms of tension. The most characteristic are the emergence of anxiety and emotional experience of the stressful circumstances of the working environment: signs of the symptom of experiencing psychotraumatic circumstances are diagnosed in $64.4 \%$ of seafarers, $32.6 \%$ of respondents show signs of dissatisfaction with themselves, their chosen profession, position or duties they perform, a decrease in self-esteem. $37.1 \%$ of seafarers have signs of the "cornered" symptom, which is characterized by a sense of hopelessness, helplessness, and the realization that you are guided by circumstances. $44.7 \%$ of respondents reveal a sign of situational and personal anxiety, which is the most important symptom of the first burnout phase.

More than a third of the surveyed seafarers (37.8\%) at the significant level reveal the formation of the exhaustion symptom. This symptom is characterized by personal and emotional detachment, psychosomatic and psycho-vegetative disorders. In $33.4 \%$ of the subjects, a symptom of "emotional deficiency" was found, which is characterized by an awareness of one's own failure, trying to exclude both positive and negative emotions from the professional sphere.

The symptom of "personal detachment" (or "depersonalization") is expressed in $34.85 \%$ of the subjects. Signs of this symptom among sailors is, first of all, the loss of interest to colleagues as subjects of communication.

As for the symptom of "psychosomatic and psycho-vegetative detachment", $51.52 \%$ of respondents speak about the appearance of headaches, problems with the cardiovascular system, with sleep, the need for taking medication to improve well-being and mood. But, it 
should be said that psychosomatic reactions occur in seafarers even during the tension phase, when symptoms of anxiety and depression occur.

The data obtained give us the right to argue that seafarers need the help of specialists to overcome and prevent professional burnout.

It should be emphasized that when developing programs for integrated rehabilitation of the crew, it is necessary to take into account the psychological characteristics of the contingent in order to conduct psychological correction, which can be aimed at developing coping mechanisms (coping behavior) with the most frequent stress situations, developing conflict resolution skills $[9,10]$. This allows the use of methods of behavior modification, psychological counseling, aimed at resolving the conflict, for example, in positive psychotherapy. With group forms of work, these approaches allow for fairly intense exposure in a short time.

Psychocorrectional work can also be aimed at developing skills for self-regulation of emotional states through the use of suggestive therapy, autogenic training or a combination of them, as well as at optimizing psychological defense mechanisms - dynamically oriented therapy, gestalt therapy and the practice of narrative using narrative cards M. White's [11, 12]. Rehabilitation measures with marked signs of professional burnout of a sailor can be aimed at optimizing the structures of psychological protection and the formation of quoting behavior. Engineering approaches for the formation of competencies are quite complex [13, 14].

We have developed a technology for the prevention of professional burnout in seafarers. The training will amount to 20 academic hours: the main part - 4 sections, 4 acad. hours for each section; 2 Acad. h. - Introduction to the training; 2 Acad. h. - Completion of training. The purpose of the training: the formation of seafarers skills to counter stress, as the main factor determining emotional burnout and self-regulation skills. Training objectives: 1) familiarization of training participants with the content and structure of professional burnout; 2) mastering by participants of the training methods of diagnosing personal characteristics that can contribute to or counteract the development of the syndrome of emotional burnout; 3) mastering by participants of the training skills and skills to counter stress, as the main factor determining emotional burnout and self-regulation skills. The structure of the training "Prevention of professional burnout among sailors" is presented in Table. 1. 
Table 1. The structure of the training "prevention of professional burnout at sailors".

\begin{tabular}{|c|c|}
\hline Training sections & Training components \\
\hline \multicolumn{2}{|c|}{ Entry into the training (2 hours) } \\
\hline \multirow{3}{*}{$\begin{array}{l}\text { Module } 1 . \\
\text { "The concept of } \\
\text { professional burnout and } \\
\text { its role in the activities of } \\
\text { the seaman" }\end{array}$} & $\begin{array}{l}\text { Content-semantic component: "Analysis of the essence of professional } \\
\text { burnout" }\end{array}$ \\
\hline & $\begin{array}{l}\text { Diagnostic component "Diagnosis of signs of emotional burnout and their } \\
\text { characteristics" }\end{array}$ \\
\hline & $\begin{array}{l}\text { Correctional and developing component: "Conditions for the prevention } \\
\text { of burnout in sailors" }\end{array}$ \\
\hline \multirow{3}{*}{$\begin{array}{l}\text { Module } 2 . \\
\text { "Types and causes of } \\
\text { professional stress } \\
\text { among sailors" (4 hours) }\end{array}$} & $\begin{array}{l}\text { Content-semantic component: "Analysis of the types and causes of } \\
\text { professional stress in seafarers" }\end{array}$ \\
\hline & $\begin{array}{l}\text { Diagnostic component "Diagnosis of the presence and level of stress in } \\
\text { sailors" }\end{array}$ \\
\hline & $\begin{array}{l}\text { Correctional and developing component: "Methods for the prevention } \\
\text { and control of stress" }\end{array}$ \\
\hline \multirow{3}{*}{$\begin{array}{l}\text { Module 3. "The content } \\
\text { and structure of the } \\
\text { psychological readiness } \\
\text { of seafarers to prevent } \\
\text { professional burnout" } \\
\text { (4 hrs.) }\end{array}$} & $\begin{array}{l}\text { Content-semantic component: "Analysis of the essence of psychological } \\
\text { readiness to prevent professional burnout in sailors" }\end{array}$ \\
\hline & $\begin{array}{l}\text { Diagnostic component "Diagnosis of the components of psychological } \\
\text { readiness for professional burnout" }\end{array}$ \\
\hline & $\begin{array}{l}\text { Correctional and developmental component: "Conditions for the } \\
\text { formation of psychological readiness to prevent professional burnout } \\
\text { among sailors" }\end{array}$ \\
\hline \multirow{3}{*}{$\begin{array}{l}\text { Module } 4 . \text { "Factors of } \\
\text { formation } \\
\text { psychological readiness } \\
\text { for the prevention of } \\
\text { professional burnout" (4 } \\
\text { hours) }\end{array}$} & $\begin{array}{l}\text { Content-semantic component: "Analysis of micro and meso-level factors } \\
\text { that influence the onset of symptoms of professional burnout and the } \\
\text { formation of psychological readiness for the prevention of professional } \\
\text { burnout in sailors" }\end{array}$ \\
\hline & $\begin{array}{l}\text { Diagnostic component "Diagnostics of factors of formation of } \\
\text { psychological readiness to prevent professional burnout among seafarers" }\end{array}$ \\
\hline & $\begin{array}{l}\text { Correctional and developing component: "How to take into account } \\
\text { the factors of psychological readiness to prevent professional burnout? } \\
\text { Development of skills to counter stress and self-regulation" }\end{array}$ \\
\hline \multicolumn{2}{|c|}{ Summing up the training ( 2 hours) } \\
\hline
\end{tabular}

The first module of the training is devoted to the analysis of the essence of the concept of "professional burnout". The second module of the training concerns the identification and analysis of the types and causes of symptoms of professional burnout. The third module of the training is devoted to the analysis of the general content of the psychological readiness of seafarers to prevent professional burnout, and methods of dealing with stress. The fourth module of the training concerns the analysis of factors affecting the prevention of professional burnout (micro and meso level factors).

Each of the modules, according to the technological approach, consists of three blocks: a) content-semantic (the essence of a certain phenomenon is revealed) b) diagnostic (certain manifestations of the phenomenon are diagnosed) c) correctional-developmental (directions and conditions of correction and development of certain indicators are determined concerning the phenomenon under study). Such interactive techniques are used for their implementation: 
The content-semantic component was realized with the help of such techniques:

- multimedia presentation (presentation of the overall design, the main stages of the training and individual semantic issues with the involvement of information sources and the results of trainers' own research);

- mini-lectures ("classic" and with the help of information technology);

- filling in worksheets (studying expectations; disclosing the content of the basic concepts of the topic, etc.);

- method of unfinished proposals (with subsequent group discussion) intergroup discussion (presentation by the working groups of the results of certain tasks;

- formulation of clarifying and problematic issues; answers to questions posed, etc.);

- "brainstorming" method (individual, doubles and group options) photo presentation (presentation of photographic materials made during training with a digital camera, and their demonstration using a multimedia projector on the screen), etc.

\section{Conclusion}

The diagnostic component was implemented using such techniques:

- psychological workshop (performing diagnostic tasks);

- analysis and discussion of the results of performing diagnostic tasks (at the individual and group levels);

- performance of individual and group tasks, etc.

Correction-developing component was carried out using such techniques:

- performance of creative tasks and their presentation in the form of diagrams, drawings, etc ;

- analysis of the manifestation of symptoms of professional burnout (discussion of real problem situations and the search for optimal solutions to them);

- conducting business and role-playing games (simulation of real situations of manifestation of symptoms of professional burnout and the search for the best options for their solution and prevention);

- building individual and group correctional development programs (development of selfregulation skills and skills to counteract stress as the main factor determining emotional burnout);

- Reflection of occupation (individual; group), etc.

During the development of the content of these interactive techniques, the designs of I. Avidon, A. Alekhina, L. Karamushki, V. Mihailenko, E. Fil $[2,10]$ were mainly used.

Findings. As a result of prolonged stressful states, emotional burnout is a complex phenomenon. Its symptoms are manifested in the fact that a person is experiencing depression, fatigue, dissatisfaction with his work, in particular, and life in general. Since the work of marine occupations is associated with extreme situations, emotional and physical overloads, they are at risk and are subject to the development of emotional, psychological burnout syndrome. To prevent burnout and minimize the effects of stressors, it is necessary to carry out social and psychological work with people whose work is accompanied by stressful situations. 


\section{References}

1. K. A. Abulkhanova-Slavskaya, On the Ways of Building a Personality Typology, Psychol. Magazine, v. 2, 1, p. 24 (1983)

2. I. Avidon, Interaction training in the conflict. Materials for the preparation and conduct, 192 p. (Saint-petersburg, Speech, 2008)

3. V. S. Ageev, Inter-group interaction: socio-psychological problems, 240 p. (Moscow: Moscow State University Publishing House, 1990)

4. B. G. Ananyev, Man as a Subject of Knowledge, 339 p. (L.: LSU, 1968)

5. Yu. A. Aleksandrovsky, States of mental maladjustment and their compensation (Moscow, 2002)

6. V. V. Boyko, The energy of emotion in communication: viglyad on themselves and others, 472 p. (Moscow, Information and publishing house "Filin", 1996)

7. V. V. Boyko, Psychoenergy, 416 p. (Saint-petersburg, Peter, 2008)

8. V. A. Ganzen, V. N. Yurchenko, A systematic approach to the analysis, description and experimental study of human mental states, Mental states, Experimental and applied psychology, Issue 10, 321 p. (Leningrad, 1981)

9. O. A. Istomina, Socio-psychological characteristics of sea crews in conditions of long voyages, Transport of the Russian Federation, 12, p. 121-132 (Moscow, 2007)

10. L. M. Karamushka, Formation of a competitive management team (based on the work of educational organizations): monograph, 268 p. (K.: INKOS, 2007)

11. M. White, Re-engaging with history: The absent but implicit. In M. White (Ed.), Reflections on narrative practice: Essays and interviews, pp. 35-58, (Adelaide, Australia: Dulwich Center Publications, 2000)

12. M. White, Re-engaging with history: The absent but implicit. In M. White (Ed.), Reflections on narrative practice: Essays and interviews, pp. 35-58 (Adelaide, Australia: Dulwich Center Publications, 2000).

13. S. Sokolov, A. Zhilenkov, S. Chernyi, A. Nyrkov and D. Mamunts, "Dynamics Models of Synchronized Piecewise Linear Discrete Chaotic Systems of High Order", Symmetry, vol. 11, no. 2, p. 236, (2019) Available: 10.3390/sym11020236.

14. N. Glebov, A. Zhilenkov, S. Chernyi and S. Sokolov, "Process of the Positioning Complex Modeling Objects with Elements of Intellectual Analysis", Procedia Computer Science, vol. 150, pp. 609-615 (2019) Available: 10.1016/j.procs.2019.02.094 